Jurnal Kimia Sains dan Aplikasi 25(1)(2022):34-40
ISSN: 1410-8917
Jurnal

\title{
Kinetics of Formation and Characterization of Green Silver Nanoparticles of Ficus variegata Leaf Extract
}

\author{
Synodalia C. Wattimena ${ }^{\mathrm{a}, *}$, Violin Ririmasse ${ }^{\mathrm{a}}$, Amos Killay ${ }^{\mathrm{a}}$, Philipus J. Patty ${ }^{\mathrm{b}}$ \\ a Department of Biology, FMIPA, Universitas Pattimura, Ambon, Indonesia \\ ${ }^{\mathrm{b}}$ Department of Physics, FMIPA, Universitas Pattimura, Ambon, Indonesia \\ *Corresponding author: cynthia.wattimena@gmail.com
}

https://doi.org/10.14710/jksa.25.1.34-40

\begin{tabular}{l}
\hline Article Info \\
\hline Article history: \\
Received: $27^{\text {th }}$ July 2021 \\
Revised: $13^{\text {th }}$ January 2022 \\
Accepted: $28^{\text {th }}$ January 2022 \\
Online: $31^{\text {st }}$ January 2022 \\
Keywords: \\
Silver nanoparticles; \\
Antibacterial activity; Ficus \\
variegata; Kinetics of Formation
\end{tabular}

\begin{abstract}
This study aimed to determine the formation rate of silver nanoparticles synthesized using leaf extract of Ficus variegata and characterize their physical, chemical, and antibacterial properties against Gram-positive Staphylococcus aureus and Gram-negative Escherichia coli. For the formation rate determination, an empirical exponential model was proposed and used to fit the absorbance vs. time data (kinetics data). The surface plasmon resonance wavelength was measured using UV-Vis spectroscopy for physical and chemical characterization. The shape and size of the silver nanoparticles were characterized by transmission electron microscopy (TEM), and organic materials on the surface of the particles were identified by characterizing the associated chemical bonding using FTIR spectroscopy. For antibacterial assays, disc diffusion and spectrophotometric methods were used. The formation rates of the silver nanoparticles were $0.036 \mathrm{per}$ hour or $1.0 \times 10^{-5} \mathrm{~s}^{-1}$ (slower rate) and 0.767 per hour or $2.1 \times 10^{-4} \mathrm{~s}^{-1}$ (faster rate). UV-Vis absorption spectrum indicated the surface plasmon resonance peak at 415 $\mathrm{nm}$. Silver nanoparticles formed mainly were spherical, with a mean diameter of $26.5 \pm 0.7 \mathrm{~nm}$. The FTIR spectrum indicated the presence of organic materials on the surface of the silver nanoparticles, which indicated the involvement of the extract as a reducing agent in particles formation. Antibacterial assay showed that synthesized silver nanoparticles inhibited the growth of both $S$. aureus and E. coli. The results from the disc diffusion method imply that the particles inhibited the growth of E. coli more effectively than $S$. aureus.
\end{abstract}

\section{Introduction}

Silver nanoparticles (AgNPs) have been of interest in academics and industries, among other metal nanoparticles, such as gold, platinum, and iron. This is due to their wide range of applications. One of the wellknown properties of AgNPs is their antibacterial property, and many products in the industry have used AgNPs because of this property, i.e., food packaging [1], textile [2], cosmetics [3], dental fillings [4], and medical devices [5]. Besides their antibacterial properties, silver nanoparticles also have some other unique properties which make them applicable in many industrial products, for instance, optical properties for biosensors [6], electronic properties for paper electronics [7], thermal properties for nanofluid [8], and biological properties for drug delivery systems [9].

AgNPs can be obtained by physical, chemical, and biological methods. Although each method has its advantages and disadvantages, the biological method has been a popular choice recently because it is affordable, easy to use, and non-toxic or environmentally friendly [10]. In that method, the production of AgNPs is mediated by microorganisms or plant extracts, where plant extracts have some advantages compared to the microorganism in dealing with cell culture. The number of studies of silver nanoparticles using plant extract increased exponentially from 2001 to 2019, where different parts of the plant, such as leaves, seeds, barks, fruit, roots, were used [11]. Plant extract components play 
a role as a reducing agent to reduce $\mathrm{Ag}^{+}$becoming $\mathrm{Ag}^{\circ}$ so that the AgNPs can be formed.

Characterization of AgNPs produced using leaf extract has been done by many researchers. The characterization includes physical, chemical, antifungal, antibacterial, anticancer, antioxidant, antibacterial, and anti-inflammatory $[12,13,14]$. One parameter of the physical properties of AgNPs, which is not studied intensively, is the formation rate of the particles, an important parameter to study the reaction of the AgNPs formation [15]. The formation rate parameter can be used to control the process of AgNPs synthesis [16]. The physical, chemical, and antibacterial properties of AgNPs, can be used to analyze the interrelation between AgNPs synthesis parameters. Some previous studies have determined the formation rate of AgNPs [15, 16, 17]. However, all these studies of the kinetic formation of AgNPs used the absorbance vs. time data of several minutes up to 2 hours measurements.

In comparison, the kinetics data of other previous studies showed that it took several hours, even more than a day, for the absorbance to reach a plateau value, after increasing in the first few minutes to a few hours $[18,19]$. An increase in the absorbance in the first few minutes denotes the formation of the particles, and it ceases to increase when the formation is completed. This means that more data is required over several days to determine the formation rate, from the initial to the complete formation of the particle, which was done in this new study.

The leaf extract of Ficus variegata was chosen as a reducing agent. Indonesians use these leaves as a traditional medicine to treat various diseases such as dysentery and ulceration. The leaves contain secondary metabolites such as alkaloids, flavonoids, and steroids/terpenoids, which have antibacterial and antioxidant activities $[20,21]$. This study aims to determine the formation rate of AgNPs synthesized using leaf extract of Ficus variegata and characterize their physical, chemical, and antibacterial properties. The results can reveal the possible interrelation between synthesis parameters of AgNPs.

\section{Methodology}

\subsection{Synthesis of AgNPs}

Synthesis of AgNPs followed the protocol described previously $[12,22]$. The leaves of Ficus variegata were collected from the local garden in Ambon, Indonesia, and cleaned consecutively with tap water followed by distilled water to remove the dust on their surfaces. Twenty grams of the washed leaves were cut into small pieces and put into $200 \mathrm{~mL}$ distilled water. The mixture was heated for 20 minutes and left to cool. The cooled mixture was filtered through a Whatman filter No.1 to obtain the extract. AgNPs were prepared by mixing the extract with $1 \mathrm{mM} \mathrm{AgNO}_{3}$ solution (volume ratio of 1:9).

\subsection{Determination of Formation Rate of AgNPs}

The formation rate was determined by fitting an empirical exponential model of:

$$
A=A_{0}\left(1-A_{1} e^{-k_{1} t}-A_{2} e^{-k_{2} t}\right)
$$

The absorbance vs. time data (kinetics data) of the sample was measured from when the silver nitrate solution was mixed with the extract until the AgNPs were completed to form. In this model, $A$ and $t$ are the absorbance and time, respectively, and $A_{s}$ and $k_{s}$ are the fitting parameters: $A_{s}$ are related to the absorbance, where $A_{o}$ is the maximum absorbance, $k_{1}$ and $k_{2}$ are the rate formation which in this case, two rates inferred empirically from the data. The goodness of the fit parameters is indicated by $\chi^{2}$ defined by:

$$
\chi^{2}=\frac{1}{N-m} \sum_{i=1}^{N} \frac{\left(y_{i}-f_{i}\right)^{2}}{\sigma_{i}^{2}}
$$

Where $N$ is the number of data and $m$ is the number of parameters, $y_{i}, f_{i}$, and $\sigma_{i}$ is the data, fit, and uncertainty of the data, respectively, at a given measurement time. The model function of Equation 1 was fitted to the absorbance vs. time data by using a non-linear fitting routine to find the smallest value of $\chi^{2}$. The absorbance of the sample was measured using Colorimeter Smart 2 LaMotte with a light source wavelength of $430 \mathrm{~nm}$.

\subsection{Physical and Chemical Characterization of AgNPs}

Physical and chemical characterizations of AgNPs included the determination of the localized surface plasmon resonance wavelength (LSPR wavelength), measurements of the diameters, and identification of the functional group of AgNPs. UV-Vis spectrophotometer (UV-1700 PharmaSpec Shimadzu), owned by the Department of Chemistry at Pattimura University, was used to determine the LSPR wavelength of AgNPs. For UV-Vis measurements, $3.5 \mathrm{~mL}$ of the sample was filled into a 10x10 mm optical path cuvette, and the sample was scanned with a light wavelength varying from 300 to 600 nm.

TEM (JEOL JEM 1400), owned by the Department of Chemistry at Gadjah Mada University, was used to measure the diameter of AgNPs. A small drop of AgNPs was put onto a $\mathrm{Cu}$-substrated grid and left to dry for TEM measurement. The functional group of AgNPs was identified using FTIR Spectrophotometer (8201 PC Shimadzu) owned by the Department of Chemistry at Gadjah Mada University. For FTIR sample preparation, suspension of AgNPs was centrifuged at 12,000 rpm for 20 minutes to obtain the pellet, where for the measurement, $2 \mathrm{mg}$ of the pellet was mixed with $200 \mathrm{mg} \mathrm{KBr}$.

\subsection{Antibacterial Assay of AgNPs}

For the antibacterial assay, two methods were involved: disc diffusion and spectrophotometric methods. For the disc diffusion method, a total of $200 \mu \mathrm{L}$ of fresh bacterial suspension ( $1.5 \times 108 \mathrm{CFU} / \mathrm{mL})$ was pipetted and spread on the surface of the NA medium and allowed to dry. After that, $20 \mu \mathrm{l}$ of AgNPs were pipetted onto a paper disk with $0.6 \mathrm{~cm}$ in diameter. The dried paper disk was then placed on the surface of the solidified media and incubated at $35-37^{\circ} \mathrm{C}$ for 24 hours. This test was carried out using $E$. coli or $S$. aureus with three replicates for each bacterium. After the incubation time, measurements of the inhibition zones were investigated. 
For the spectrophotometric method, approximately $5 \mathrm{~mL}$ of the AgNPs, $5 \mathrm{~mL}$ of sodium broth, and $500 \mu \mathrm{l}$ of bacterial suspension were put into a sterile bottle and incubated at room temperature. In another sterile bottle, $5 \mathrm{~mL}$ of sterile distilled water, $5 \mathrm{~mL}$ of sodium broth, and $500 \mu \mathrm{l}$ of bacterial suspension were mixed for the control. This test was carried out using E. coli and S. aureus with three replicates for each bacterium. The bottles were incubated at room temperature for 24 hours. The absorbances were then measured with the wavelength of $620 \mathrm{~nm}$ using a colorimeter for a specific incubation time.

\section{Results and Discussion}

\subsection{Kinetics of the Formation of the AgNPs}

The formation of AgNPs took place a few minutes after mixing silver nitrate solution with the extract, which is indicated by the change of color of the mixture from transparent to yellowish-brown. It is believed that the secondary metabolites contained in leaf extracts, such as alkaloids, flavonoids, and steroids/terpenoids, act as a reducing agent to reduce $\mathrm{Ag}^{+}$to $\mathrm{Ag}^{0}$, which initiates the process of nucleation, and eventually forms AgNPs [23].

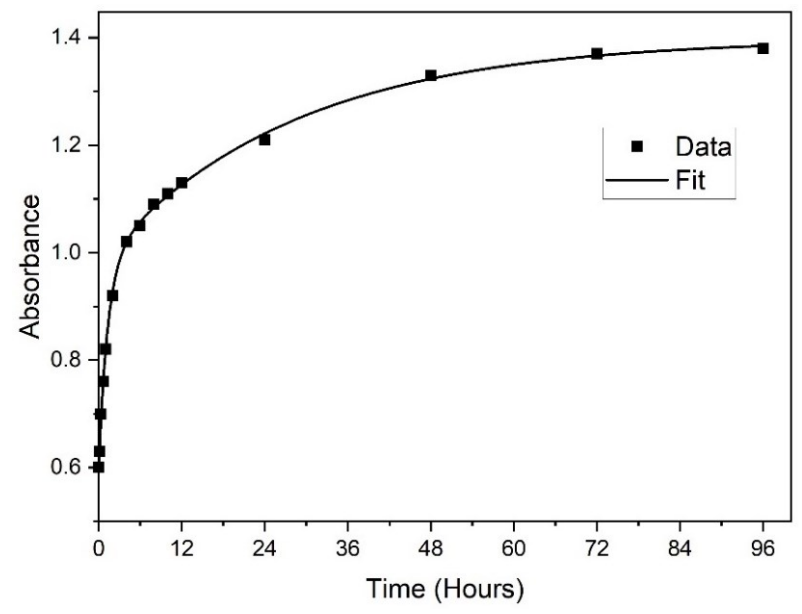

Figure 1. Absorption of the AgNPs was measured as a function of time for three days. The line is the fit of the model to the data

For the kinetics of the AgNPs formation, the absorbance of the sample was measured after mixing silver nitrate solution with the extract. There was a change in the color of the sample from transparent to yellowish-brown. At the same time, the absorbance of the sample increased. The change of color and the increase in absorbance were related to the formation of the AgNPs. Figure 1 shows the graph of absorbance as a function of time in three days, using a $430 \mathrm{~nm}$ wavelength light source. The figure shows that the absorbance increased exponentially, reaching a plateau in less than 24 hours. The increase in absorbance was due to the formation of the AgNPs. The pattern in the figure indicates that the number of AgNPs formed increased exponentially, and the plateau denoted that all AgNPs have been formed.

To determine the formation rate, an exponential model of Equation 1 fit the data. The fitting process was conducted to obtain $A_{o}, A_{1}, A_{2}, k_{1}$, and $k_{2}$ (the five fitting parameters) using a non-linear fitting routine to find the smallest value of $\chi^{2}$. The parameters resulting from the fits are summarized in Table 1 . The value of $\chi^{2}$ as an indicator of the goodness of fit parameters was $7.35 \times 10^{-5}$. The Anova analysis showed $\mathrm{p}<0.05$, which is a good indicator of consistency between the data and the model, thus the validity of the fitting results.

Table 1. The value of parameters from the fits

\begin{tabular}{cccc}
\hline No & Parameters & Value & Standard Error \\
\hline 1 & $A_{o}$ & 1.40 & 0.01 \\
2 & $A_{1}$ & -0.274 & 0.009 \\
3 & $A_{2}$ & -0.299 & 0.007 \\
4 & $k_{1}$ & $0.036 /$ hour & $0.0034 /$ hour \\
5 & $k_{2}$ & $0.767 /$ hour & $0.05 /$ hour \\
\hline
\end{tabular}

The line in Figure 1 is an Equation 1 curve with the value of fitting parameters taken from fitting results shown in Table 1 . The formation rates $k_{1}$ and $k_{2}$ resulting from the fit were found to be $0.036 /$ hour or $1.0 \times 10^{-5} \mathrm{~s}^{-1}$ and $0.767 /$ hour or $2.1 \times 10^{-4} \mathrm{~s}^{-1}$, respectively. The more significant formation rate was indicated at the beginning, wherein the first 6 hours, the absorbance increased rapidly, and later it became slower, associated with the lower formation rate. The formation rate of AgNPs was previously studied using Musa balbisiana peel extract, where the rate was found to be $4.35 \times 10^{-4}[15]$, in the same order as more significant formation rate of AgNPs of this study. Nevertheless, the data used to get the formation rate of Musa balbisiana AgNPs was only up to 2 hours (no plateau observed), compared to AgNPs using Ficus variegata of this study which covers three day-data, where the plateau was observed. The formation of AgNPs is complete when the plateau is reached. This study gave an alternative model to determine the formation rate of AgNPs, which is consistent with the data and can cover a wide range of data, from initial to complete formation.

\subsection{Physical and Chemical Characterizations of the AgNPs}

The yellowish-brown color of the AgNPs observed (Inset, Figure 2) was a unique color of the sample. On the surface of the AgNPs, there was a collective vibration of electrons known as Plasmon. The vibration frequency is related to the color of the sample, thus the wavelength, which is a characteristic wavelength of the sample. When light with this wavelength impinged on the sample, the sample would absorb the light, and the resonance took place, called a localized surface plasmon resonance (LSPR).

UV-Vis was used to characterize the LSPR wavelength of the sample, and Figure 2 shows the spectrum of UV-Vis for AgNPs together with the picture of the sample (inset). The figure indicates that the LSPR wavelength of AgNPs was $415 \mathrm{~nm}$. This value of LSPR wavelength was in the interval range of LSPR wavelength of AgNPs, 400-500 nm. Some previous studies, for example, also showed the values of LSPR wavelength in this interval range: LSPR wavelength of $415 \mathrm{~nm}$ of Syzygium aromaticum AgNPs [12], $430 \mathrm{~nm}$ for Astragalus tribuloides AgNPs [14], and $440 \mathrm{~nm}$ for Tectona grandis AgNPs [24], and $455 \mathrm{~nm}$ for Graptophyllum pictum AgNPs [22]. 


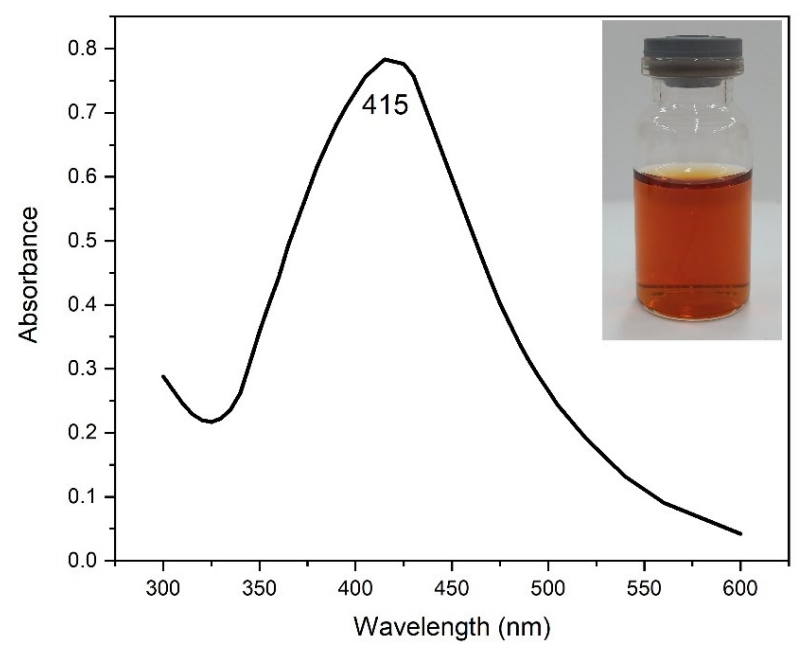

Figure 2. UV-Vis spectrum of AgNPs together with the picture of the sample

Figure 3 (Top) shows TEM of the AgNPs with different magnifications. The particles are mostly spherical, and for the particle size determination, 100 particles were chosen randomly for the analysis. The diameter of the particles measured varied from the minimum value of $10.0 \mathrm{~nm}$ to the maximum value of 40.5 $\mathrm{nm}$. The mean diameter of the particles was determined to be $26.5 \pm 0.7 \mathrm{~nm}$, and the particle size distribution is shown in Figure 3 (Bottom).
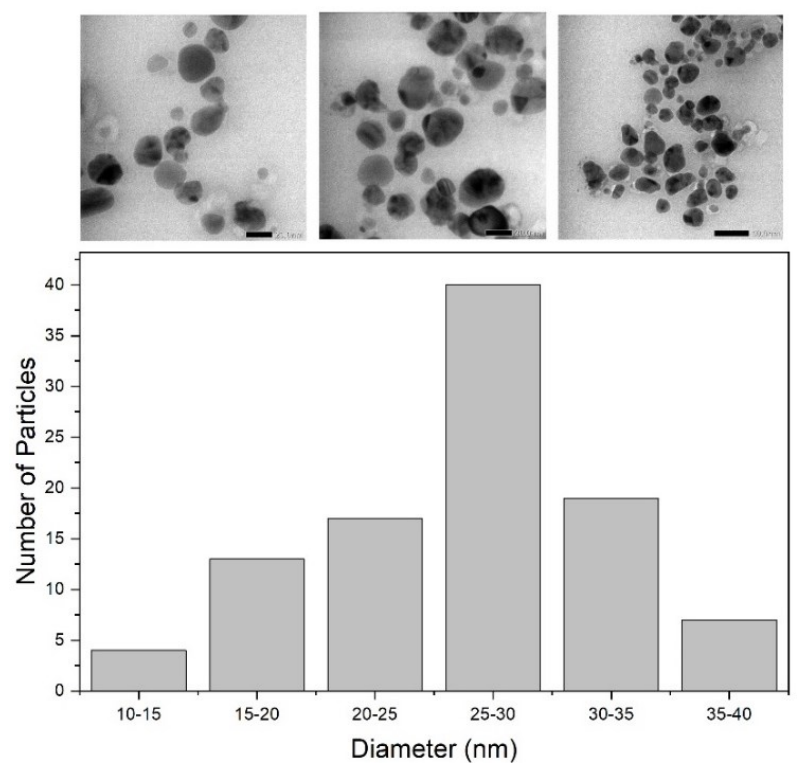

Figure 3. TEM of the AgNPs at two different magnifications and the particle size distribution

Figure 4 shows the FTIR spectrum of the AgNPs. The peak at $3425 \mathrm{~cm}^{-1}$ is related to a hydrogen-bonded $\mathrm{O}-\mathrm{H}$ stretching, while peaks at 2924 and $2846 \mathrm{~cm}^{-1}$ associate with $\mathrm{CH}_{2}$ asymmetric and symmetric stretching, respectively. The peak at $1627 \mathrm{~cm}^{-1}$ corresponds to $\mathrm{C}=\mathrm{O}$ stretching, while peaks at 1381 and $1064 \mathrm{~cm}^{-1}$ respectively signal an $\mathrm{O}-\mathrm{H}$ bend and a $\mathrm{C}-\mathrm{C}-\mathrm{O}$ stretching. These results indicate the presence of organic materials on the surface of AgNPs; thus, it is proven that the extract contributes to the formation of particles as a reducing agent and capping agent.

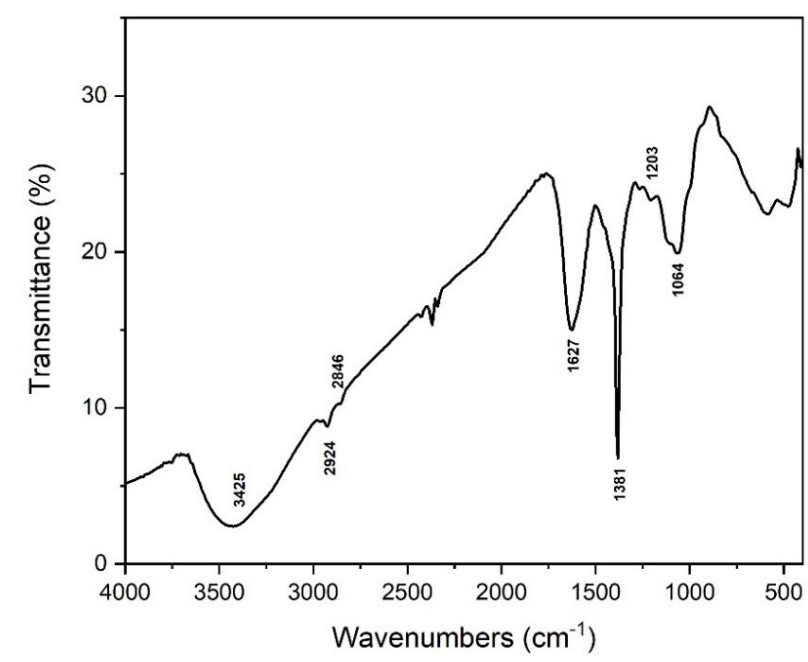

Figure 4. FTIR spectrum of the AgNPs

\subsubsection{Antibacterial Characterization of AgNPs}

Antibacterial properties of the AgNPs against E. coli and $S$. aureus were characterized using both disc diffusion and spectrophotometric methods. Figure 5A shows the results of antibacterial characterization against $E$. coli using the disc diffusion method with three replicates of the inhibition zones. The mean diameter of the inhibition zones was found to be $17.8 \pm 1.2 \mathrm{~mm}$. Figure $5 \mathrm{~B}$ shows the results of antibacterial characterization against $E$. coli using a spectrophotometric method. The results indicates that OD- 620 of the bacterial sample increased in 24 -hour observation, while OD-620 of the bacterial sample mixed with the AgNPs was relatively constant. An increase in OD-620 of bacterial sample denoted the growth of the bacteria, while a constant value of OD-620 of bacterial sample mixed with the AgNPs indicated the role of AgNPs in inhibiting bacterial growth. Statistical analysis results showed a significant difference between OD-620 of the two samples starting from hour 4 of the observation. This suggested that AgNPs significantly inhibited the growth of E. coli 4 hours after the application of the AgNPs.
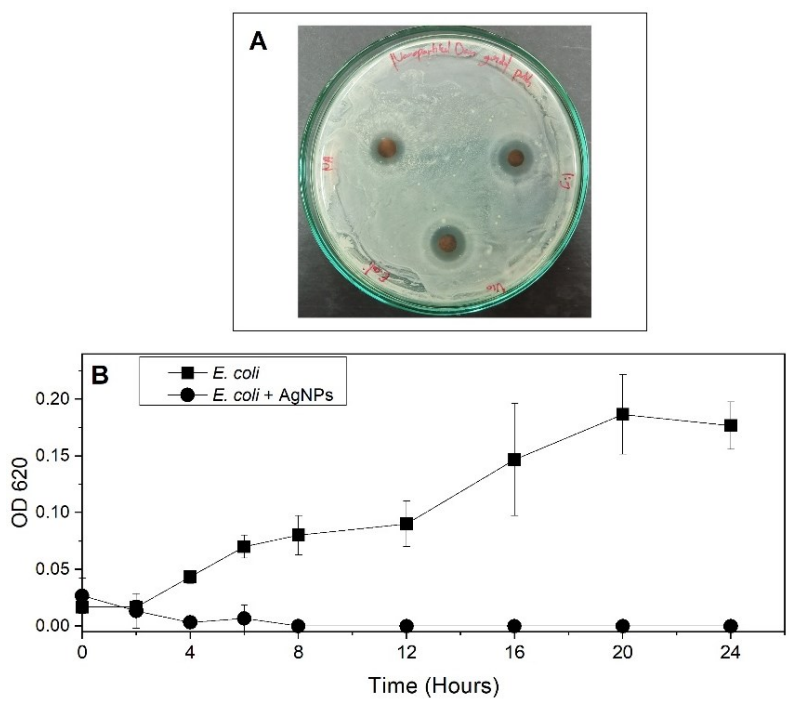

Figure 5. A) Inhibition zones of the AgNPs against E. coli of a diffusion disc method, and B) OD-620 of E. coli sample and E. coli sample mixed with the AgNPs of spectrophotometric method 
Figure $6 \mathrm{~A}$ shows the results of antibacterial characterization against $S$. aureus using a disc diffusion method with three replicates of the inhibition zones. The mean diameter of the inhibition zones was found to be $14.0 \pm 0.5 \mathrm{~mm}$. Figure $6 \mathrm{~B}$ shows the results of antibacterial characterization against $S$. aureus using a spectrophotometric method. Similar to the E. coli sample results, an increase in OD- 620 of the $S$. aureus sample denoted the growth of the bacteria, while a constant value of OD- 620 of the $S$. aureus sample mixed with the AgNPs indicated the role of AgNPs in inhibiting $S$. aureus growth. The statistical analysis of $S$. aureus data suggested that AgNPs significantly inhibited the growth of S. aureus 4 hours after applying the AgNPs.

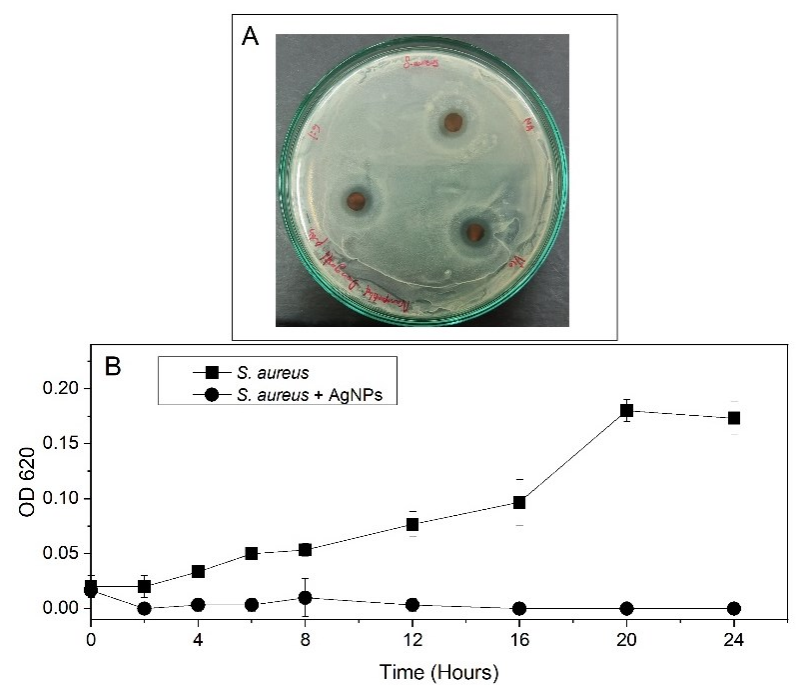

Figure 6. A) Inhibition zones of the AgNPs against $S$. aureus of a diffusion disc method, and B) OD-620 of $S$. aureus sample and $S$. aureus sample mixed with the AgNPs of a spectrophotometric method

The results of antibacterial characterization from both disc diffusion and spectrophotometric methods showed the ability of the AgNPs to inhibit the growth of both E. coli and S. aureus. One of the possible mechanisms of the antibacterial effect of AgNPs was the release of $\mathrm{Ag}^{+}$ ions [25], which can interact electrostatically with the negatively charged cytoplasmic membrane and can penetrate the interior of the cell, where the ions deactivate respiratory enzymes and stimulate the formation of reactive oxygen species [26]. In addition, the small size of AgNPs shown by the mean diameter of $26.5 \pm 0.7 \mathrm{~nm}$ associated with a high surface area to volume ratio of the particles, in which the percentage of atoms at the surface became dominant, which is beneficial for the release of more $\mathrm{Ag}^{+}$for an antibacterial effect. Moreover, the small size of AgNPs physically favored the interaction between the particles and the cell wall for particles to penetrate the cell wall and change the membrane structure, which eventually lyses the cell.

The antibacterial assay results from the spectrophotometric methods, where AgNPs inhibited the growth of both $E$. coli and S. aureus 4 hours after their application, indicated that AgNPs showed no difference in inhibiting the growth of $E$. coli and $S$ aureus. This is in contrast with the results from previous studies showing that AgNPs inhibited the growth of $E$. coli faster than $S$. aureus [12, 27].

The antibacterial assay results from the disc diffusion method indicated that the mean diameter of the inhibition zones of $E$. coli was more significant than that of $S$. aureus. Statistical analysis showed that the inhibition zones of $E$. coli are significantly larger than that of $S$. aureus ( $t$-test, $\rho<0.05$ ). This suggested that the AgNPs inhibited the growth of $E$. coli more effectively than $S$. aureus. The results obtained are in accordance with some previous studies using green AgNPs [14, 24, 28, 29]. The explanation for these results is that the cell wall of $E$. coli is thinner than the cell wall of $S$. aureus. In contrast, some previous studies showed no difference in AgNPs inhibiting the growth of E. coli and S. aureus [12, 30]. Some studies showed the other way around: AgNPs inhibited the growth of $S$. aureus more effectively than E. coli [31, 32].

Interestingly, another study showed that AgNPs are more effective in inhibiting the growth of $S$. aureus than of E. coli at a small concentration of AgNPs. In contrast, the opposite effect was observed on a high concentration of AgNPs [33]. All these results suggested that the thickness of the bacteria cell wall is not the only factor affecting the ability of AgNPs to inhibit the growth of bacteria.

\section{Conclusion}

This study showed that silver nanoparticles can be synthesized using Ficus variegata leaf extract. The formation of silver nanoparticles was indicated by the change of color of the sample from transparent to yellowish-brown after mixing the extract with silver nitrate solution. The formation rates determined by fitting an empirical exponential model to the kinetic data were found to be $0.036 /$ hour or $1.0 \times 10^{-5} \mathrm{~s}^{-1}$ and $0.767 /$ hour or $2.1 \times 10^{-4} \mathrm{~s}^{-1}$. The spectrum of UV-Vis of the sample confirmed the formation of the particles showing the wavelength of surface plasmon resonance of $415 \mathrm{~nm}$. Silver nanoparticles formed mainly were spherical, with diameters varying from $10.0 \mathrm{~nm}$ to $40.5 \mathrm{~nm}$ and a mean diameter of $26.5 \pm 0.7 \mathrm{~nm}$. The FTIR spectrum revealed the presence of extract compounds on the surface of the silver nanoparticles, which indicated the involvement of the extract as a reducing agent in particles formation. Antibacterial assay using disc diffusion and spectrophotometric methods showed that silver nanoparticles synthesized using leaf extract of Ficus variegata inhibit $S$. aureus and $E$. coli. The results from disc diffusion methods implied that the particles inhibit the growth of E. coli more effectively than $S$. aureus.

\section{References}

[1] Arsi Istiqola, Achmad Syafiuddin, A review of silver nanoparticles in food packaging technologies: Regulation, methods, properties, migration, and future challenges, Journal of the Chinese Chemical Society, 67, 11, (2020), 1942-1956 https://doi.org/10.1002/jccs.202000179

[2] Daniela Ballottin, Stephanie Fulaz, Flavia Cabrini, Junko Tsukamoto, Nelson Duran, Oswaldo L. Alves, Ljubica Tasic, Antimicrobial textiles: Biogenic silver nanoparticles against Candida and Xanthomonas, 
Materials Science and Engineering: C, 75, (2017), 582589 https://doi.org/10.1016/j.msec.2017.02.110

[3] Georgios Fytianos, Abbas Rahdar, George Z. Kyzas, Nanomaterials in Cosmetics: Recent updates, Nanomaterials, 10, 5, (2020), 979

https://doi.org/10.3390/nano10050979

[4] Thaís Yumi Umeda Suzuki, Juno Gallego, Wirley Gonçalves Assunção, André Luiz Fraga Briso, Paulo Henrique Dos Santos, Influence of silver nanoparticle solution on the mechanical properties of resin cements and intrarradicular dentin, PLoS One, 14, 6, (2019), e0217750

https://doi.org/10.1371/journal.pone.0217750

[5] Valentina Marassi, Luisana Di Cristo, Stephen G. J. Smith, Simona Ortelli, Magda Blosi, Anna L. Costa, Pierluigi Reschiglian, Yuri Volkov, Adriele PrinaMello, Silver nanoparticles as a medical device in healthcare settings: a five-step approach for candidate screening of coating agents, Royal Society Open Science, 5, 1, (2018), 171113 https://doi.org/10.1098/rsos.171113

[6] Alexis Loiseau, Victoire Asila, Gabriel Boitel-Aullen, Mylan Lam, Michèle Salmain, Souhir Boujday, Silver-based plasmonic nanoparticles for and their use in biosensing, Biosensors, 9, 2, (2019), 78 https://doi.org/10.3390/bios9020078

[7] Lixin Mo, Zhenxin Guo, Zhenguo Wang, Li Yang, Yi Fang, Zhiqing Xin, Xiu Li, Yinjie Chen, Meijuan Cao, Qingqing Zhang, Nano-silver ink of high conductivity and low sintering temperature for paper electronics, Nanoscale Research Letters, 14, 1, (2019), 1-11

https://doi.org/10.1186/s11671-019-3011-1

[8] S. Iyahraja, J. Selwin Rajadurai, Study of thermal conductivity enhancement of aqueous suspensions containing silver nanoparticles, AIP Advances, 5, 5, (2015), 057103 https://doi.org/10.1063/1.4919808

[9] Helena I. O. Gomes, Catarina S. M. Martins, João A. V. Prior, Silver Nanoparticles as Carriers of Anticancer Drugs for Efficient Target Treatment of Cancer Cells, Nanomaterials, 11, 4, (2021), 964 https://doi.org/10.3390/nano11040964

[10] Cheah Liang Keat, Azila Aziz, Ahmad M. Eid, Nagib A. Elmarzugi, Biosynthesis of nanoparticles and silver nanoparticles, Bioresources and Bioprocessing, 2, 1, (2015), 1-11

https://doi.org/10.1186/s40643-015-0076-2

[11] Chhangte Vanlalveni, Samuel Lallianrawna, Ayushi Biswas, Manickam Selvaraj, Bishwajit Changmai, Samuel Lalthazuala Rokhum, Green synthesis of silver nanoparticles using plant extracts and their antimicrobial activities: A review of recent literature, RSC Advances, 11, 5, (2021), 2804-2837 https://doi.org/10.1039/DoRA09941D

[12] S. C. Wattimena, A. A. Reniwuryaan, P. J. Patty, Physical-chemical and antibacterial properties of green-synthesized silver nanoparticles mediated by leaf extract of Syzygium aromaticum L, Journal of Physics: Conference Series, 2021 https://doi.org/10.1088/1742-6596/1825/1/012090

[13] Tunas Alam, Frida Octavia Purnomo, Asbar Tanjung, Antimicrobial Activities of Synthesized Silver Nanoparticles using Ethanol and Water Extract of Mirabilis Jalapa, Jurnal Kimia Sains dan
Aplikasi, 24, 3, (2021), 70-76

https://doi.org/10.14710/jksa.24.3.70-76

[14] Majid Sharifi-Rad, Pawel Pohl, Francesco Epifano, José M. Álvarez-Suarez, Green synthesis of silver nanoparticles using Astragalus tribuloides delile. root extract: Characterization, antioxidant, antibacterial, and anti-inflammatory activities, Nanomaterials, 10, 12, (2020), 2383 https://doi.org/10.3390/nano10122383

[15] Wara Dyah Pita Rengga, Dhimas Setiawan, Khosiatun Khosiatun, Biosynthesis and kinetics of silver nanoparticles formation by reduction using banana kepok (Musa balbisiana) peel extract, ASEAN Journal of Chemical Engineering, 17, 2, (2017), 77-85 https://doi.org/10.22146/ajche.49557

[16] Iqbal M. Ismail, Hassan A. Ewais, Mechanistic and kinetic study of the formation of silver nanoparticles by reduction of silver (I) in the presence of surfactants and macromolecules, Transition Metal Chemistry, 40, 4, (2015), 371-378 https://doi.org/10.1007/s11243-015-9926-1

[17] V. I. Kuz'min, A. F. Gadzaov, D. L. Tytik, S. A. Busev, A. A. Revina, Formation kinetics of silver nanoparticles in reverse micelles. 3. Reductant concentration and temperature as factors controlling synthesis of nanoparticles, Colloid Journal, 77, 6, (2015), 733-744 https://doi.org/10.1134/S1061933X15050130

[18] Synodalia C. Wattimena, Philipus J. Patty, Synthesis of Silver Nanoparticles Mediated by Stem Extract of Anredera cordifolia and Study of Their Antimicrobial Properties, The Pharmaceutical and Chemical Journal, 4, 5, (2017), 129-136

[19] Synodalia C. Wattimena, Philipus J. Patty, Antibacterial Properties of Silver Nanoparticles Synthesized Using Leaf Extract of Anredera cordifolia as a Reducing Agent, World Journal of Pharmacy and Pharmaceutical Sciences, 6, 12, (2017), 1673-1683

[20] Rolan Rusli, Bela Apriliana Ningsih, Agung Rahmadani, Lizma Febrina, Vina Maulidya, Jaka Fadraersada, Isolation and Antioxidant and Antibacterial Activity of Flavonoid from Ficus variegate Blume, Indonesian Journal of Chemistry, 19, 2, (2019), 538-543

https://doi.org/10.22146/ijc.23947

[21] Rolan Rusli, Myra Puspha Hardina, Fairul Muflihah, Agung Rahmadani, Profil kromatografi senyawa aktif antioksidan dan antibakteri fraksi n-heksana daun Libo (Ficus variegata Blume), Journal of Tropical Pharmacy Chemistry, 3, 2, (2015), 124-130 http://dx.doi.org/10.25026/jtpc.v3i2.98

[22] S. C. Wattimena, D. R. Silooy, P. J. Patty, Characterization of green silver nanoparticles of Graptophyllum pictum leaf extract: from the localized surface plasmon resonance to the antimicrobial activity, Journal of Physics: Conference Series, 2021 https://doi.org/10.1088/1742-6596/1943/1/012065

[23] Zahra Vaseghi, Ali Nematollahzadeh, Omid Tavakoli, Green methods for the synthesis of metal nanoparticles using biogenic reducing agents: a review, Reviews in Chemical Engineering, 34, 4, (2018), 529-559 https://doi.org/10.1515/revce-2017-0005

[24] Akhil Rautela, Jyoti Rani, Mira Debnath Das, Green synthesis of silver nanoparticles from Tectona 
grandis seeds extract: characterization and mechanism of antimicrobial action on different microorganisms, Journal of Analytical Science Technology, 10, 1, (2019), 1-10

https://doi.org/10.1186/s40543-018-0163-z

[25] Yi-Huang Hsueh, Kuen-Song Lin, Wan-Ju Ke, Chien-Te Hsieh, Chao-Lung Chiang, Dong-Ying Tzou, Shih-Tung Liu, The antimicrobial properties of silver nanoparticles in Bacillus subtilis are mediated by released $\mathrm{Ag}^{+}$ions, PloS One, 10, 12, (2015), e0144306

https://doi.org/10.1371/journal.pone.0144306

[26] Lucía Z. Flores-López, Heriberto Espinoza-Gómez, Ratnasamy Somanathan, Silver nanoparticles: Electron transfer, reactive oxygen species, oxidative stress, beneficial and toxicological effects. Mini review, Journal of Applied Toxicology, 39, 1, (2019), 16-26 https://doi.org/10.1002/jat.3654

[27] Soo-Hwan Kim, Hyeong-Seon Lee, Deok-Seon Ryu, Soo-Jae Choi, Dong-Seok Lee, Antibacterial activity of silver-nanoparticles against Staphylococcus aureus and Escherichia coli, Korean Journal of Microbiology and Biotechnology, 39, 1, (2011), 77-85

[28] Haytham M. M. Ibrahim, Green synthesis and characterization of silver nanoparticles using banana peel extract and their antimicrobial activity against representative microorganisms, Journal of Radiation Research and Applied Sciences, 8, 3, (2015), 265-275 https://doi.org/10.1016/j.jrras.2015.01.007

[29] S. Rajeshkumar, Synthesis of silver nanoparticles using fresh bark of Pongamia pinnata and characterization of its antibacterial activity against gram positive and gram negative pathogens, Resource-Efficient Technologies, 2, 1, (2016), 30-35 https://doi.org/10.1016/j.reffit.2016.06.003

[30] Tri Puji Lestari, Fitia Abbas Tahlib, Johan Sukweenadhi, Kartini Kartini, Christina Avanti, Physical Characteristic and Antibacterial Activity of Silver Nanoparticles from Green Synthesis Using Ethanol Extracts of Phaleria macrocarpa (Scheff.) Boerl Leaves, Majalah Obat Tradisional, 24, 1, (2019), 16-21 https://doi.org/10.22146/mot.37956

[31] Kongara M. Reddy, Kevin Feris, Jason Bell, Denise G. Wingett, Cory Hanley, Alex Punnoose, Selective toxicity of zinc oxide nanoparticles to prokaryotic and eukaryotic systems, Applied Physics Letters, 90, 21, (2007), 213902 https://doi.org/10.1063/1.2742324

[32] Zarrindokht Emami-Karvani, Pegah Chehrazi, Antibacterial activity of ZnO nanoparticle on grampositive and gram-negative bacteria, African Journal of Microbiology Research, 5, 12, (2011), 1368-1373 http://dx.doi.org/10.5897/AJMR10.159

[33] Álvaro de Jesús Ruíz-Baltazar, Simón Yobbany Reyes-López, Daniel Larrañaga, Miriam Estévez, Ramiro Pérez, Green synthesis of silver nanoparticles using a Melissa officinalis leaf extract with antibacterial properties, Results in Physics, 7, (2017), 2639-2643

https://doi.org/10.1016/J.RINP.2017.07.044 